DOE/PC/94204--T3

FREE-RAD COAL 6-94

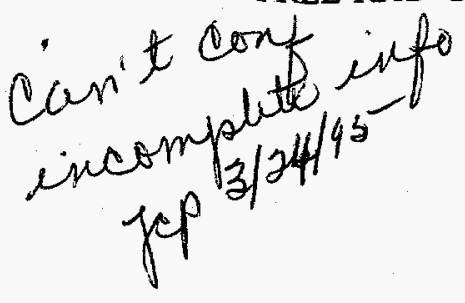

\title{
FREE-RADICAL KINETICS OF COAL LIQUEFACTION
}

\author{
Ming Wang, J.M. Smith, Ben J. McCoy* \\ Department of Chemical Engineering and Materials Science \\ University of California \\ Davis, CA 95616 \\ FAX 916-752-1031 \\ bjmccoy@ucdavis.edu
}

\begin{abstract}
A rate expression with first- and second-order terms in the concentration of extractable compounds in solid coal particles is derived from a fundamental freeradical mechanism. The expression was suggested empirically by prior experiments for coal liquefaction in the presence of a hydrogen-donor solvent. Radical reactions are considered to occur in both coal and in solvent. The long-chain approximation justifies the neglect of initiation, hydrogen abstraction, and termination rates as quantitatively insignificant relative to propagation reaction rates.
\end{abstract}

\section{Introduction}

Coal liquefaction proceeds through a complex free-radical process. ${ }^{1}$ In the absence of strong hydrogen-donor solvent, first-order kinetics usually can describe the formation rate of dissolved product. 2,3,4 In the presence of a strong donor solvent (e.g., tetralin) the reactions are not as simple.5,6,7,8,9 Wang et al. 10 described experimental data for coal thermolysis in a mixed solvent of tert-butyl alcohol and tetralin by a rate expression that included first-and second-order terms in the concentration, C, of extractable compounds in the solid coal particles. An empirical rate equation of similar form was employed by Kang et al.11 to describe their coal liquefaction data. Curran et al.12 initially pointed out the significance of the relationship between the extent of coal conversion to soluble products and the amount of hydrogen transferred to these products. This concept, supported by the general observation that radical reactions control the thermal decomposition of most 
organic substances, was reinforced by the discovery of free radicals in coal by

Uebersfeld et al. ${ }^{13}$ and the experimental results of electron-spin-resonance (ESR) spectrometry. ${ }^{14,15}$ Detailed mechanisms for initiation, propagation, and termination reactions were proposed by Attar ${ }^{16}$ and Gun.17,18

In a recent examination of the long-chain approximation of Gavalas, ${ }^{19} \mathrm{Nigam}$ et al. ${ }^{20}$ modeled complex reactions of radicals by representing the rate as the sum of initiation and long-chain rates. The result was a rate expression consisting of two terms: one first-order in reactant concentration, $\mathrm{A}$, and a second of the form $\alpha_{1}$ $A^{3 / 2} /\left(1+\alpha_{2} A\right)$. The approach has significant possibilities for treating other complex reaction systems involving free-radicals.

Our current objective is to develop a kinetic model for coal liquefaction and thermolytic and supercritical extraction experiments in the presence of hydrogendonor solvent. The development is based on the long-chain approximation for a complex mechanism of radical reactions, ${ }^{19}$ and leads to a reaction rate expression with first-and second-order terms. The second-order term appears when the principal mechanism for free-radical termination is hydrogen abstraction from the donor solvent.

\section{Theoretical Background}

When coal is heated the products are determined by the reactions of radicals formed by bond scission. 21 When the radicals have no access to an external hydrogen donor, the radicals may abstract hydrogen from the already hydrogen-poor coal molecular network, or combine with other large radical fragments to form a high molecular-weight insoluble residue. When a hydrogen donor is present, the radical may abstract hydrogen from the donor and form a relatively low molecular weight product. The reaction sequence of Curran et al. 12 focused on the scission of carbon-carbon bonds in coal molecules. The initial step is thermal decomposition,

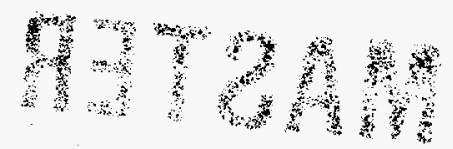




\section{DISCLAIMER}

This report was prepared as an account of work sponsored by an agency of the United States Government. Neither the United States Government nor any agency thereof, nor any of their employees, make any warranty, express or implied, or assumes any legal liability or responsibility for the accuracy, completeness, or usefulness of any information, apparatus, product, or process disclosed, or represents that its use would not infringe privately owned rights. Reference herein to any specific commercial product, process, or service by trade name, trademark, manufacturer, or otherwise does not necessarily constitute or imply its endorsement, recommendation, or favoring by the United States Government or any agency thereof. The views and opinions of authors expressed herein do not necessarily state or reflect those of the United States Government or any agency thereof. 


\section{DISCLAIMER}

Portions of this document may be illegible in electronic image products. Images are produced from the best available original document. 
which produces radicals that are stabilized by capture of hydrogen atoms from donor molecules or, less effectively, from within the coal itself.

Gun et al.17,18 examined the individual roles of temperature, hydrogen-donor solvent, and catalyst in the mechanism of liquefaction. It was supposed that stable products can be produced by abstracting hydrogen atoms from hydrogen-donor molecules and through intramolecular and intermolecular rearrangement reactions. The derivation produced the kinetic expression,

$$
d\left[P_{m}\right] / d t=\beta_{1} C+\beta_{2} C^{2}+\beta_{3}
$$

where $\beta_{1}, \beta_{2}$, and $\beta_{3}$ are functions of hydrogen-donor concentration. The zero-order term, $\beta_{3}$, is typically much smaller than $\beta_{1} C$ and $\beta_{2} C^{2}$. Three aspects of this mechanism can be modified and improved. First, the sites where all the free-radical reactions occur are not specified. Radical reactions occurring both on the coal surface and in the liquid phase may play important roles in the coal liquefaction. 22 Second, not all the enhancement processes of hydrogen-donor solvents are represented in this mechanism. Third, since most good hydrogen donors are hydroaromatic compounds 23 , the hydrogen transfer can be described in greater detail. Tetralin, for example, is a model hydrogen donor from which a donor radical can be formed by abstraction of a hydrogen atom. This radical can continue to donate another hydrogen atom to form a stable molecule, dihydronaphthalene. In the proposed mechanism that follows we include these processes.

\section{Modified Free-Radical Mechanism}

Petrakis et al.24,15 made a systematic investigation of the free radicals during coal liquefaction using ESR spectroscopy. They found coal heated with naphthalene has the highest spin concentration, followed by the coal heated in tetralin, and then with the coal only (pyrolysis). The results agree with the expectation that naphthalene would not tend to quench free radicals as efficiently as tetralin, which is a good hydrogen donor. To explain why the spin concentration of the coal-only run 
is lower than that of the tetralin run, we suggest that the presence of solvent can partially stabilize the free radicals. Thus, radicals formed in the thermal degradation will be more stable in donor solvent than in the pyrolysis run. This implies that the total concentration of radicals is higher when a solvent is present. Some radicals formed on the solid surface of coal particles could dissolve in the stagnant film of solvent after the initiation. Then, radicals both on the coal surface and in the solvent continue to undergo a series of chemical reactions to form stable products. Based on these concepts the following mechanism can be proposed.

Suppose $F_{n}$ is a group of free radicals having molecular weight $n, F_{(n-m)}{ }^{\bullet}$ is a group of radicals with molecular weight $n-m$, and $P_{m} \cdot$ is a group of radicals of molecular weight $m$. The indexes $n, n-m$, and $m$ represent ranges of molecular weights, where in general, $m$ is much smaller than $n$. The subscripts $s$ and $l$ denote coal surface and stagnant film of solvent respectively. In the initiation reaction weak bonds in the macromolecular network are decomposed by thermal cleavage, yielding radicals. Thermal effects are the main driving force in initiating the extraction process, and subsequent progress depends on the interaction of the coal-derived radicals. The extent of the reaction, or conversion, is a measure of the primary and secondary formation and stabilization of radicals. The radicals formed in the initiation process will either migrate on the coal particle surface or dissolve into the surrounding film of solvent. In the absence of a hydrogen donor these radicals can be stabilized only through intramolecular or intermolecular rearrangements, which leads to a group of products denoted as $P_{m l}$ and $P_{m s}$. The significant reaction between a radical and coal, reaction (4) below, is not included in some earlier models.

In the scheme with strong donor solvent, $\mathrm{DH}_{2}$ denotes the hydrogen donor (e.g., tetralin); DH• corresponds to a radical produced by abstraction of one hydrogen atom from the solvent molecule; $\mathrm{D}$ represents a molecule produced by abstraction of two hydrogen atoms. The radicals formed in the initiation stage can be stabilized by 
capture of hydrogen atoms from donor molecules or from within the coal itself. There are three pathways available for such stabilization: (1) H-abstraction from the solvent or from a hydrogen-rich portion of the coal; (2) elimination of part of the radical molecule by associated group migration, or rearrangement to form another more stable structure; (3) a combination reaction such as condensation or alkylation with another molecule in the solvent, which could be a radical. The presence and type of hydrogen donors will determine the preferred reaction path ${ }^{23}$ represented in the proposed mechanism. The coal-derived radicals $\left(F_{n^{*}}\right.$ and $\left.P_{m^{*}}\right)$ are large (molecular weight of 300-3000) and contain several aromatic rings. Therefore they have a small translational motion. The donor molecules and radicals are smaller and much more mobile on the solid surface and in the solution. Hence, the abstraction reaction is more important than the intermolecular rearrangement reactions. Another function of donor solvent is to enhance the intermolecular rearrangement as a hydrogen carrier, that is, to move hydrogen atoms from one coal fragment to another.

\section{Reactions on the Coal Surface}

Initiation reaction (thermal cleavage, molecular dimensions $m<n-m<n$ )

$\mathrm{C}($ coal $) \longrightarrow \mathrm{F}_{\mathrm{ns}}{ }^{*}+\mathrm{P}_{\mathrm{ms}}{ }^{\bullet} \quad \mathrm{k}_{1}$

Propagation (intramolecular rearrangement)

$$
\begin{array}{ll}
F_{n s^{*}} \longrightarrow P_{m s}+F_{(n-m) s^{*}} & k_{2} \\
F_{n s^{*}} \longrightarrow P_{m s^{*}}+C_{1} \text { (insoluble residue) } & k_{3} \\
P_{m s^{*}}+C(\text { coal }) \longrightarrow P_{m s}+F_{n s^{*}} & k_{4}
\end{array}
$$

Termination (intermolecular rearrangement)

$$
\begin{aligned}
& \mathrm{F}_{\mathrm{ns}}{ }^{\bullet}+\mathrm{P}_{\mathrm{ms}} \mathrm{s}^{-} \longrightarrow \mathrm{C}_{1} \text { (residue) }+\mathrm{P}_{\mathrm{ms}} \quad \mathrm{k}_{5} \\
& \mathrm{~F}_{\mathrm{ns}}{ }^{*}+\mathrm{F}_{\mathrm{ns}} \mathrm{s}^{*} \longrightarrow \mathrm{C}_{1} \text { (residue) }+\mathrm{P}_{\mathrm{ms}} \quad \mathrm{k}_{6} \\
& \mathrm{P}_{\mathrm{ms}} \cdot+\mathrm{P}_{\mathrm{ms}} \cdot \longrightarrow \mathrm{P}_{\mathrm{ms}} \longrightarrow \mathrm{k}_{7} \\
& \mathrm{~F}_{(\mathrm{n}-\mathrm{m}) \mathrm{s}^{\bullet}}+\mathrm{P}_{\mathrm{ms}} \mathrm{s}^{\bullet} \longrightarrow \mathrm{C}_{1} \text { (residue) }+\mathrm{P}_{\mathrm{ms}} \quad \mathrm{k}_{5}{ }^{\prime}
\end{aligned}
$$




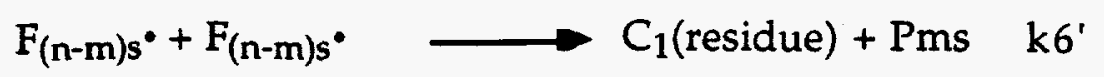

Hydrogen abstraction from donor

$$
\begin{array}{ll}
\mathrm{P}_{\mathrm{ms}^{\bullet}}+\left(\mathrm{DH}_{2}\right)_{\mathrm{s}} \longrightarrow \mathrm{P}_{\mathrm{ms}}+(\mathrm{DH} \cdot)_{\mathrm{s}} & \mathrm{k}_{8} \\
\mathrm{P}_{\mathrm{ms}}+(\mathrm{DH})_{\mathrm{s}} \longrightarrow \mathrm{P}_{\mathrm{ms}}+\mathrm{D}_{\mathrm{s}} & \mathrm{k}_{9} \\
\mathrm{~F}_{\mathrm{ns}}+(\mathrm{DH})_{\mathrm{s}} \longrightarrow \mathrm{C}_{1}+(\mathrm{DH} \cdot)_{s} & \mathrm{k}_{10} \\
\mathrm{~F}_{\mathrm{ns}}+(\mathrm{DH} \cdot)_{\mathrm{s}} \longrightarrow \mathrm{C}_{1}+\mathrm{D}_{\mathrm{s}} & \mathrm{k}_{11} \\
\mathrm{~F}(\mathrm{n}-\mathrm{m}) \mathrm{s}^{\bullet}+\left(\mathrm{DH}_{2}\right)_{\mathrm{s}} \longrightarrow \mathrm{C}_{1}+(\mathrm{DH} \cdot)_{\mathrm{s}} & \mathrm{k} 10^{\prime} \\
\mathrm{F}(\mathrm{n}-\mathrm{m}) \mathrm{s}^{\bullet}+(\mathrm{DH} \cdot)_{s} \longrightarrow \mathrm{C}_{1}+\mathrm{D}_{\mathrm{s}} & \mathrm{k}_{11}
\end{array}
$$

Adsorption and Desorption between Coal and Fluid

$$
\begin{aligned}
& \mathrm{F}_{\mathrm{ns}} \stackrel{\mathrm{k}_{12}}{\stackrel{\mathrm{k}_{13}}{\rightleftharpoons}} \mathrm{F}_{\mathrm{nl}} \mathrm{K}^{\bullet} \quad \mathrm{K}_{\mathrm{F}}=\mathrm{k}_{12} / \mathrm{k}_{13} \\
& F_{(n-m) s^{\bullet}} \stackrel{k_{12}}{\underset{k_{13}}{\rightleftharpoons}} F_{(n-m) l^{\bullet}} \quad K_{F^{\prime}}=k_{12^{\prime}} / k_{13^{\prime}} \\
& \mathrm{P}_{\mathrm{ms}} \stackrel{\mathrm{k}_{14}}{\stackrel{\mathrm{k}_{15}}{\rightleftharpoons}} \mathrm{P}_{\mathrm{ml}^{*}} \quad \mathrm{~K}_{\mathrm{P}}=\mathrm{k}_{14} / \mathrm{k}_{15} \\
& \left(\mathrm{DH}_{2}\right)_{s} \stackrel{\mathrm{k}_{18}}{\stackrel{\mathrm{k}_{19}}{\rightleftharpoons}}\left(\mathrm{DH}_{2}\right)_{1} \quad \mathrm{~K}_{\mathrm{DH} 2}=\mathrm{k}_{18} / \mathrm{k}_{19} \\
& (\mathrm{DH} \cdot)_{s} \stackrel{\mathrm{k}_{20}}{\underset{\mathrm{k}_{21}}{\rightleftharpoons}}(\mathrm{DH} \cdot)_{1} \quad \mathrm{~K}_{\mathrm{DH}}=\mathrm{k}_{20} / \mathrm{k}_{21} \\
& D_{s} \stackrel{k_{22}}{\underset{k_{23}}{\rightleftharpoons}} D_{1} \quad K_{D}=k_{22} / k_{23}
\end{aligned}
$$

Reactions in the Stagnant Film of Solvent

Propagation (intramolecular rearrangement)

$$
\begin{array}{ll}
\mathrm{F}_{\mathrm{n} l^{*}} \longrightarrow \mathrm{P}_{\mathrm{ml}}+\mathrm{F}_{(\mathrm{n}-\mathrm{m}) l^{*}} & \mathrm{k}_{24} \\
\mathrm{~F}_{\mathrm{nl}} \mathrm{P}^{*} \longrightarrow \mathrm{P}_{\mathrm{ml}^{*}}+\mathrm{C}_{1} & \mathrm{k}_{25}
\end{array}
$$

Termination (intermolecular rearrangement)

$$
\mathrm{F}_{\mathrm{nl}^{*}}+\mathrm{P}_{\mathrm{ml}} \mathbf{l}^{\bullet} \longrightarrow \mathrm{C}_{1}+\mathrm{P}_{\mathrm{ml}} \quad \mathrm{k}_{26}
$$




$$
\begin{aligned}
& \mathrm{F}_{\mathrm{nl}}{ }^{\bullet}+\mathrm{F}_{\mathrm{nl}} \cdot \longrightarrow \mathrm{C}_{1}+\mathrm{P}_{\mathrm{ml}} \longrightarrow \mathrm{k}_{27} \\
& \mathrm{P}_{\mathrm{ml}^{*}}+\mathrm{P}_{\mathrm{ml}}{ }^{*} \longrightarrow \mathrm{P}_{\mathrm{ml}} \quad \mathrm{k}_{28} \\
& \mathrm{~F}_{(\mathrm{n}-\mathrm{m}) \mathrm{l}^{*}}+\mathrm{P}_{\mathrm{ml}} \mathrm{l}^{*} \longrightarrow \mathrm{C}_{1}+\mathrm{P}_{\mathrm{ml}} \longrightarrow \mathrm{k}_{26^{\prime}} \\
& \mathrm{F}_{(\mathrm{n}-\mathrm{m}) \mathrm{l}^{\bullet}}+\mathrm{F}_{(\mathrm{n}-\mathrm{m}) \mathrm{l}^{\bullet}} \longrightarrow \mathrm{C}_{1}+\mathrm{P}_{\mathrm{ml}} \longrightarrow \mathrm{k}_{27^{\prime}}
\end{aligned}
$$

Hydrogen abstraction from donor

$$
\begin{aligned}
& \mathrm{P}_{\mathrm{ml}}+\left(\mathrm{DH}_{2}\right)_{1} \longrightarrow \mathrm{P}_{\mathrm{ml}}+\left(\mathrm{DH}^{\bullet}\right)_{1} \quad \mathrm{k}_{29} \\
& \mathrm{P}_{\mathrm{ml}}+(\mathrm{DH} \cdot)_{1} \longrightarrow \mathrm{P}_{\mathrm{ml}}+\mathrm{D}_{1} \quad \mathrm{k}_{30} \\
& \mathrm{Fnl}^{\bullet}+\left(\mathrm{DH}_{2}\right)_{\mathrm{l}} \longrightarrow \mathrm{C}_{1}+(\mathrm{DH} \cdot)_{l} \mathrm{k}_{31} \\
& \mathrm{Fnl}^{\bullet}+(\mathrm{DH} \cdot)_{1} \longrightarrow \mathrm{C}_{1}+\mathrm{D}_{1} \mathrm{k}_{32}
\end{aligned}
$$

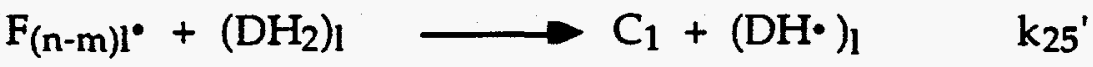

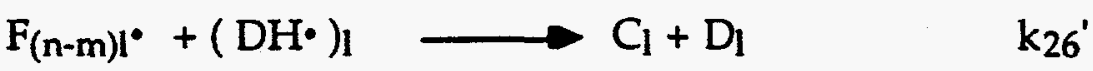

\section{Rate Expressions}

Derivation of the rate expressions is based on the following assumptions:

1. For both radicals and stable molecules, internal and external diffusion resistances are negligible for the coal particles.

2. Free-radical reactions account for all covalent-bond scission and formation processes and all hydrogen-transfer processes.

3. All the elemental reactions except the processes of adsorption and desorption are treated as irreversible reactions

4. The products formed both on the coal surface and in the stagnant film are totally soluble in the solvent, which is present in large excess.

5. The long-chain approximation ${ }^{19}$ is applicable.

6. The processes of adsorption and desorption between solid surface and solvent are at equilibrium.

Assumption 6 is based on the following arguments. Free radicals in coal chemistry include highly reactive radicals, reactive delocalized radicals, and inert radicals. 25 Highly reactive radicals do not possess resonance stabilization energy and 
are known to be highly reactive in radical-molecule reactions. Small radicals, such as $\mathrm{H}$ atoms, hydroxyl radicals, aryl radicals, and alkyl radicals, belong to this group. These radicals will be stabilized on the coal surface immediately after formation. Reactive delocalized radicals have a resonance stability resulting from odd-electron delocalization. Such radicals are stable and can build up to relatively high concentration. Most coal-related radicals belong to this group. Inert radicals are very stable and can build up to high concentrations $(>0.02 \mathrm{M}$ ) in coal pyrolysis mixtures. 26,27 Of the above groups, reactive delocalized radicals are most important in coal thermolysis. The reactions involving these radicals are relatively slow. For example, the rate constant ${ }^{25}$ for these radicals to abstract a $\mathrm{H}$ atom from tetralin at $425^{\circ} \mathrm{C}$ is $10^{-3}$ to $100 \mathrm{~s}^{-1}$. Kinetic data of adsorption and desorption for free radicals are apparently not available. Based on the data for $n-C_{4} \mathrm{H}_{10}$ absorbed on silica gel obtained at $50^{\circ} \mathrm{C}, 28$ a very approximate estimate suggests a rate constant of $10^{5} \mathrm{~s}^{-1}$ at $425^{\circ} \mathrm{C}$. These results support the adsorption-desorption equilibrium assumption, at least for delocalized radicals.

The overall kinetics in the presence of strong donor solvent can be expressed as the sum of rates for the initiation and long-chain processes:

$$
\mathrm{r}=\mathrm{d}\left[\mathrm{P}_{\mathrm{m}}\right] / \mathrm{dt}=\mathrm{r}_{\mathrm{i}}+\mathrm{r}_{\mathrm{LC}}
$$

where the rate of reactant consumption by initiation is

$$
r_{i}=k_{A} C
$$

Nigam et al. ${ }^{20}$ utilized the concept that for long chains, initiation, hydrogen abstraction, and termination rates become quantitatively insignificant compared to propagation reaction rates (assumption 5). With this approximation, a mass balance of $\mathrm{F}_{\mathrm{n}} \cdot$ leads to

$$
k_{4}\left[P_{m^{\bullet}}\right]_{s}[C]-\left(k_{2}+k_{3}\right)\left[F_{n}\right]_{s}-\left(k_{24}+k_{25}\right)\left[F_{n}\right]_{l}=0
$$

where

$$
\left[\mathrm{F}_{\mathrm{n}} \cdot\right]_{1}=\mathrm{K}_{\mathrm{F}}\left[\mathrm{F}_{\mathrm{n}} \cdot\right]_{s}
$$


Thus

$$
\left[\mathrm{F}_{\mathrm{n}} \cdot\right]_{\mathrm{s}}=\mathrm{k}_{4}\left[\mathrm{P}_{\mathrm{m}} \cdot\right]_{\mathrm{s}}[\mathrm{C}] /\left\{\left(\mathrm{k}_{2}+\mathrm{k}_{3}\right)+\mathrm{K}_{\mathrm{F}}\left(\mathrm{k}_{24}+\mathrm{k}_{25}\right)\right\}
$$

Equating initiation and termination rates and neglecting terms second-order in radical concentration gives,

$$
\begin{aligned}
k_{1} C= & k_{8}\left[P_{m^{*}}\right]_{s}\left[D H_{2}\right]_{s}+k_{10}\left[F_{n}\right]_{s}\left[D H_{2}\right]_{s}+k_{10}\left[F_{(n-m)}\right]_{s}\left[D H_{2}\right]_{s}+k_{29}\left[P_{m^{*}}\right]_{l}\left[D H_{2}\right]_{l} \\
& +k_{31}\left[F_{n} \cdot\right]_{l}\left[D H_{2}\right]_{l}+k_{25}\left[F_{(n-m)}\right]_{l}\left[D H_{2}\right]_{l}
\end{aligned}
$$

If all the rate constants for hydrogen-abstraction reactions are considered equal to $k$, and if $\left[\mathrm{DH}_{2}\right]_{s}=\left[\mathrm{DH}_{2}\right]_{l}$, this equation reduces to

$$
\begin{aligned}
\mathrm{k}_{1} \mathrm{C}= & \mathrm{k}\left[\mathrm{DH}_{2}\right]_{1}\left\{\left[\mathrm{P}_{\mathrm{m}^{*}}\right]_{s}+\left[\mathrm{F}_{\mathrm{n}^{*}}\right]_{s}+\left[\mathrm{F}_{(\mathrm{n}-\mathrm{m})^{*}}\right]_{s}+\left[\mathrm{P}_{\mathrm{m}^{*}}\right]_{l}\right. \\
& \left.+\left[\mathrm{F}_{n^{*}}\right]_{1}+\left[\mathrm{F}_{(\mathrm{n}-\mathrm{m})^{*}}\right]_{l}\right\}
\end{aligned}
$$

Defining the total concentration of free radicals, $C_{T}$, as the sum of concentrations inside the brackets \{ \} yields

$$
\mathrm{C}_{\mathrm{T}}=\mathrm{k}_{1} \mathrm{C} / \mathrm{k}\left[\mathrm{DH}_{2}\right]_{1}
$$

We further assume that the concentration of radicals, $\left[F_{(n-m)^{*}}\right]$, can be ignored relative to that of the larger radicals, and that radicals in the solid and liquid phases are equilibrated with phase partitioning coefficients $\mathrm{K}$ :

$$
\left[P_{m} \cdot\right]_{s}=\frac{C_{T}}{(1+K)\left\{1+k_{4} C /\left(k_{2}+k_{3}+K\left(k_{24}+k_{25}\right)\right)\right\}}
$$

Since in the long-chain approximation the propagation steps dominate:

$$
\left.r_{L C}=k_{4} C\left[P_{m^{*}}\right]_{s}+k_{2}\left[F_{n^{*}}\right]_{s}+k_{24}\left[F_{n^{*}}\right]_{l}=k_{4} C\left[P_{m^{*}}\right]_{s}+\left(k_{2}+k_{24} K_{F}\right) F_{n^{*}}\right]_{I}
$$

Combining (5) and (10) leads to

$$
\mathrm{r}_{\mathrm{LC}}=\mathrm{k}_{4} C\left[\mathrm{P}_{\mathrm{m}}\right]_{\mathrm{s}}\left\{1+\left(\mathrm{k}_{2}+\mathrm{k}_{24} \mathrm{~K}\right) /\left\{\left(\mathrm{k}_{2}+\mathrm{k}_{3}\right)+\mathrm{K}\left(\mathrm{k}_{24}+\mathrm{k}_{25}\right)\right\}\right.
$$

and when $\mathrm{Eq}(9)$ is substituted for $\left[\mathrm{P}_{\mathrm{m}^{*}}\right]_{s}, \mathrm{Eq}(11)$ becomes

$$
r_{L C}=k_{B} C^{2 /\left(1+k_{C} C\right)}
$$

where

$$
k_{B}=\frac{k_{1} k_{4}}{(1+K) k\left[D_{2}\right]_{1}}\left\{1+\frac{k_{2}+K k_{24}}{\left(k_{2}+k_{3}\right)+K\left(k_{24}+k_{25}\right)}\right\}
$$

and 


$$
k_{C}=\frac{k_{4}}{\left.\left(k_{2}+k_{3}\right)+k_{24}+k_{25}\right)}
$$

Substituting for $r_{i}$ and $r_{L C}$ in Eq (1) yields

$$
r==k_{A} C+k_{B} C^{2} /\left(1+k_{C} C\right)
$$

For a strong hydrogen donor,

$$
k_{4} \ll k_{2}+k_{3}+K\left(k_{24}+k_{25}\right)
$$

so that $\mathrm{Eq}(15)$ becomes

$$
r==k_{A} C+k_{B} C^{2}
$$

which the expression developed empirically by Wang et al., ${ }^{10}$ and is similar to the one proposed by Kang et al.11

The mechanism derived here by means of the long-chain approximation is different from previous ones in two respects. First, all the radical reactions are considered to occur in both coal (solid) and in solvent (liquid); second, the two types of elementary reaction proposed by Curran et al., 12 which are the reactions between radicals and coal network and the reactions with donor radicals, have been combined with the others proposed by Gun et al. ${ }^{17}$ The second-order rate term is a measure of the hydrogen-transfer effect and is especially significant in the early stages of the coal thermolysis. The rate constants in the model are functions of hydrogen-donor solvent concentration.

Acknowledgement: The support of DOE PETC Grants No. DOE DE-FG22-90PC90288 and No. DE-FG22-94PC94204 is gratefully acknowledged. 


\section{Nomenclature}

C Concentration of reactive components in coal particles

$\mathrm{C}_{\mathrm{T}} \quad$ Total concentration of free radicals

$\left[\mathrm{F}_{\left.\mathrm{n}^{*}\right] \mathrm{s}} \quad\right.$ Concentration of radicals with molecular weight dimension of $\mathrm{n}$ on the coal surface

$\left[F_{n}\right]_{l} \quad$ Concentration of radicals with molecular weight dimension of $n$ in the stagnant film of solvent

$\left[\mathrm{P}_{\mathrm{m}}\right]_{\mathrm{s}} \quad$ Concentration of radicals with molecular weight dimension of $\mathrm{m}$ on the coal surface

$\left[P_{m} \cdot\right.$ ll Concentration of radicals with molecular weight dimension of $m$ in the stagnant film of solvent

$\left[F_{(n-m)^{*}}\right]_{s}$ Concentration of radicals with the molecular weight dimension of $n-m$ on the coal surface

$\left[F_{(n-m)}\right]_{l}$ Concentration of radicals with the molecular weight dimension of $n-m$ in the stagnant film of solvent

$\left[\mathrm{DH}_{2}\right]_{\mathrm{s}}$ Concentration of hydrogen-donor solvent on the coal surface

$\left[\mathrm{DH}_{2}\right]_{1}$ Concentration of hydrogen-donor solvent in the stagnant film of solvent

$[\mathrm{DH} \cdot]_{s}$ Concentration of radicals produced by abstraction of a hydrogen atom from donor solvent molecules on the coal surface

$[\mathrm{DH} \cdot]_{s}$ Concentration of radicals produced by abstraction of a hydrogen atom from donor solvent molecules in the stagnant film of solvent

$\left[\mathrm{P}_{\mathrm{m}}\right]$ Concentration of product dissolved in the solvent

$k_{A} \quad$ First-order rate constant

$k_{B} \quad$ Second-order rate constant

$\mathrm{K}_{\mathrm{F}} \quad$ Equilibrium constant for $\left[F_{n^{*}}\right]_{s}$ and $\left[F_{n^{*}}\right]_{l}$

$r_{\mathrm{LC}} \quad$ Reaction rate from the long-chain approximation

$\mathbf{r}_{\mathbf{i}} \quad$ Reaction rate for initiation 


\section{References}

(1) Stock, L., M., Chemistry of Coal Conversion, edited by Schlosberg, R. H., Plenum Press, 1985, pp. 253-313.

(2) Krevelen, D. W. V; Heerden, C. V.; Huntjens, F. J., Fuel, 1951, 30, 253.

(3) Deshpande, G. V.; Holder, G. D.; Shah, Y. T., Ind. Eng. Chem. Process Des. E Dev., 1986, 25, 705.

(4) Zhang, C. J.; Smith, J. M.; McCoy, B. J., Supercritical Fluid Engineering Science, ACS Symposium on Supercritical Fluids, ACS Symposium Series 514, 1993, 363.

(5) Storch, H. H.; Fischer, C. H.; Hawk, C. O., U.S. Bur. Mines, Tech. Paper 654 1943.

(6) Liebenberg, B. J.; Potgieter, H. G. J., Fuel, 1973, 52, 130.

(7) Weller, S; Pelipetz, M. G.; Friedman, S., IEEC, 1951, 43, 1572.

(8) Falkum, E.; Glenn, R. A., Fuel , 1952, 31, 133.

(9) Wiser, H. W., Fuel, 1968, 47, 475.

(10) Wang, M.; Smith, J.M.; McCoy, B.J., Energy \& Fuels , 1993, 7, 78.

(11) Kang, D.; Anderson, L. L.; Wiser, W. H., Technical Report to the U. S. DOE, FE-2006-T2, 1980.

(12) Curran, A. P.; Struck, R. T.; Gorin, E., IEEC Proc. Des. \&Deo., 1967, 6, 166.

(13) Uebersfeld J.; Etienne A.; Combrisson J., Nature, 1954, 174, 614.

(14) Wooten, D. L.; Dorn, H. C.; Coleman, W. H., Fuel, 1976, 55, 224.

(15) Petrakis, L.; Grandy, D. W., Free Radicals in Coals and Synthetic Fuel, Elsevier Science Publishers, 1983.

(16) Attar, A., ACS Div. Fuel Chem. Preprints , 1978, 23(4), 118.

(17) Gun, S. R.; Sama, J. K.; Chowdhury, P. B.; Mukherjee, S. K.; Mukherjee, D. K., Fuel, 1979, 58, 171.

(18) Gun, S. R.; Sama, J. K.; Chowdhury, P. B.; Mukherjee, S. K.; Mukherjee, D. K., Fuel, 1979, 58, 176. 
(19) Gavalas, G.R., Chem. Eng. Sci. , 1966, 21, 133.

(20) Nigam, A.; Fake, D.M.; Klein, M.T., AIChE J., 1994, 40, 908.

(21) Wiser, W. H., DOE Symposium Series 40, National Technical Information Service, Springfield, VA, 1978, pp. 219-236.

(22) Finseth, D.; Hough, M.; Quiser, J. A.; Retcofsky, H. L., ACS Div. of Pet. Chem. Prepr., 1979, 24(4), 979.

(23) Whitehurst, D. D., EPRI Final Report AF-1298, Project 410, 1979.

(24) Petrakis, L.; Grandy, D. W.; Ruberto, R. G., Fuel, 1981, 60, 1013.

(25) Stein, E. S., Chemistry of Coal Conversion, edited by Schlosberg, R. H., Plenum Press, 1985, pp. 13-44.

(26) Petrakis, L.; Grandy, D. W.; Jones, G. L., Fuel, 1982, 61, 21.

(27) Retcofsky, H. L.; Thompson, M. H.; Friedel, R. A., Organic Chemistry of Coal, edited by Larsen, J. W., ACS Symposium Ser. No. 71, 1978, pp. 142-155.

(28) Schneider, P.; Smith, J. M., AIChE J., 1968, 14, 769. 